\title{
Kangxianruangan granule-containing serum mediated inhibition of hepatic oval cell differentiation into hepatocellular carcinoma cells via the Wnt-1/ $\beta$-catenin signaling pathway
}

\author{
WENQIAN TANG ${ }^{1 *}, J^{*}$ AN XUE ${ }^{2,3 *}$, LEI LUO $^{1 *}$, YAO WANG $^{4}, \mathrm{XIN} \mathrm{CAI}^{5}, \mathrm{YUQING} \mathrm{LIU}^{6}$, \\ DAWEI HUANG ${ }^{7}$, XIAODONG WANG ${ }^{7}$, TANGQING HE $^{7}$, DINGBO LU ${ }^{7}$ and FAN YANG ${ }^{1,7}$ \\ ${ }^{1}$ Health Management Centre, Hubei Provincial Hospital of Traditional Chinese Medicine, Wuhan, Hubei 430074; \\ ${ }^{2}$ Clinical College of Chinese Medicine, Hubei University of Chinese Medicine, Wuhan, Hubei 430061; \\ ${ }^{3}$ Department of Gastroenterology, Hubei Province Hospital of Integrated Traditional Chinese and Western Medicine, \\ Wuhan, Hubei 430015; ${ }^{4}$ Department of Infectious Diseases, Renmin Hospital of Wuhan University, Wuhan, Hubei 430060; \\ ${ }^{5}$ Department of Infectious Diseases, The People's Hospital of Jiangshan, Jiangshan, Zhejiang 324100; \\ ${ }^{6}$ Department of Infectious Diseases, Yancheng TCM Hospital Affiliated Nanjing University of Chinese Medicine, \\ Nanjing, Jiangsu 224001; ${ }^{7}$ Department of Hepatology, Hubei Provincial Hospital of \\ Traditional Chinese Medicine, Wuhan, Hubei 430074, P.R. China
}

Received November 5, 2020; Accepted April 27, 2021

DOI: $10.3892 / \mathrm{mmr} .2021 .12571$

\begin{abstract}
Hepatocellular carcinoma is a malignancy with poor clinical prognosis. Hepatic oval cells (HOCs) tend to differentiate into cancerous hepatocellular carcinoma cells (HCCs) in the tumor microenvironment. The purpose of the present study was to explore the role of kangxianruangan granule (KXRG)-containing serum in inhibiting the differentiation of HOCs into HCCs via the Wnt-1/ $\beta$-catenin signaling pathway. N-methyl-N'-nitro-N-nitrosoguanidine (MNNG) was applied to induce the transformation of the rat HOC cell line WB-F344 into HCCs. The overexpression plasmid, Wnt-1-up, was utilized to increase Wnt-1 expression. Subsequently, high, medium and low concentrations of KXRG were applied to MNNG-treated WB-F344 cells to assess the inhibitory effect of KXRG on cell differentiation. Flow cytometry was conducted to detect the cell cycle distribution, apoptotic rate and expression of cytokeratin-19 (CK-19) protein in cells. An immunofluorescence double staining protocol was used to detect the expression of Wnt- 1 and $\beta$-catenin. ELISAs were performed to detect $\alpha$ fetoprotein in the cell supernatants.
\end{abstract}

Correspondence to: Professor Fan Yang, Department of Hepatology, Hubei Provincial Hospital of Traditional Chinese Medicine, 856 Luoyu Road, Hongshan, Wuhan, Hubei 430074, P.R. China

E-mail: yangfan@hbhtcm.com

*Contributed equally

Key words: kangxianruangan granule-containing serum, hepatic oval cells, hepatocellular carcinoma cells, Wnt-1/ $\beta$-catenin signaling pathway
Reverse transcription-quantitative PCR and western blotting were conducted to detect the mRNA and protein expression levels of Wnt-1, $\beta$-catenin, Cyclin D1, C-myc, matrix metalloproteinase-7 (MMP-7), Axin2 and epithelial cell adhesion molecule (EpCAM) in cells. Compared with the normal group, the apoptotic rate, proportion of $\mathrm{S}$ phase cells, concentration of AFP in the cell supernatant, level of CK-19 protein, and mRNA and protein expression levels of Wnt-1, $\beta$-catenin, Cyclin D1, C-myc, MMP-7, Axin2 and EpCAM were all significantly increased in the model group. Addition of KXRG significantly reduced the aforementioned indicators compared with the model group. Moreover, Wnt-1 overexpression further increased the aforementioned indicators compared with the model group, whereas KXRG significantly inhibited these effects. The results indicated that KXRG inhibited the differentiation of HOCs into HCCs via the Wnt-1/ $\beta$-catenin signaling pathway, which suggested the potential clinical application of KXRG for the prevention of hepatocellular carcinoma.

\section{Introduction}

As the main type of primary liver cancer, hepatocellular carcinoma (HCC) is the most common malignant tumor and one of the most fatal types of cancer in the world today (1) According to the latest global cancer burden data released by the International Agency for Research on Cancer, primary liver cancer is the sixth leading cause of cancer, with 906,000 new cases per year, and is the third leading cause of mortality, with 830,000 cases per year (2). A liver cancer microenvironment, the tissue around the tumor, contains a complex mixture of non-HCC cells and extracellular matrix that has the potential to promote the occurrence and development of liver cancer (3). Epidemiological studies have revealed that 
HCC displays a unique background of chronic liver injury (4). Globally, $80 \%$ of liver cancer is caused by occult hepatitis and viral infection-induced chronic hepatitis (5). The resulting liver inflammatory response and the development of liver fibrosis and liver nodules are directly related to the formation of liver cancer (6). Moreover, before the formation of liver cancer, there is long-term development of precancerous lesions (7).

Previous evidence has suggested that the cytological origin of HCC is derived from the abnormal differentiation of stem or oval cells in the liver (8). Hepatic oval cells (HOCs) are endogenous stem cells of the liver that can differentiate into liver cells for organ regeneration or transform into liver cancer cells to form malignant tumors (9). When the liver is severely and permanently damaged and the regeneration ability of mature hepatocytes is inhibited, HOCs proliferate in large quantities, thus replacing hepatocytes to repair liver tissue (10). Under certain circumstances, atypical hyperplasia occurs. At this time, the morphological features, ultrastructure, enzymology and surface markers of liver tissue suggest that normal liver cells gradually transform to cancer cells, then to fibrosis or nodular lesions, and finally to HCC (11). The Wnt- $1 / \beta$-catenin signaling pathway serves an important role in regulating the proliferation of various types of cells and the maintenance and differentiation of stem cells (12). It has been confirmed that the abnormal activation of the Wnt- $1 / \beta$-catenin signaling pathway is one important factor in hepatocarcinogenesis induction (13). Under normal circumstances, Wnt-1 signaling is necessary for tissue repair and regeneration (14). $\beta$-catenin is a key downstream component of Wnt-1 signaling pathways and can regulate hepatocyte proliferation (15).

Kangxianruangan granule (KXRG) is a compound granule of Traditional Chinese Medicine (TCM) that is composed of Seaweed, Hawthorn, Salvia miltiorrhiza, Rhizoma Curcumae, Carapax Trionycis and Oyster. In TCM it is considered that KXRG can treat liver fibrosis and cirrhosis (data not available). However, whether KXRG alters the liver cancer microenvironment via anti-liver fibrosis mechanisms, promotes HOC differentiation into normal hepatocytes, inhibits abnormal HOC proliferation or induces HOC apoptosis, thereby delaying or blocking the occurrence and development of liver cancer precancerous lesions is not completely understood. The molecular pharmacological mechanism underlying KXRG function in liver protection requires clarification.

In the present study, serum pharmacological methods were adopted to investigate the effects of KXRG on HOCs and the molecular changes that are related to the Wnt-1/ $\beta$-catenin signaling pathway. The aim was to therefore clarify the internal mechanisms underlying $\mathrm{KXRG}$ and its role in blocking the formation of hepatic precancerous lesions. The present study provided a foundation for understanding the mechanisms underlying inhibition of fibrosis in liver cancer via the Wnt/ $\beta$-catenin signaling pathway, identifying a potential treatment option for patients with HCC.

\section{Materials and methods}

Reagents. The rat HOC cell line WB-F344 was purchased from China Center for Type Culture Collection. KXRG was bought from Hubei Provincial Hospital of
Traditional Chinese Medicine. DMEM and FBS were purchased from Gibco (Thermo Fisher Scientific, Inc.). N-methyl-N'-nitro-N-nitrosoguanidine (MNNG) was purchased from Sigma-Aldrich (Merck KGaA). The Cell Counting Kit-8 (CCK-8) assay was bought from Dojindo Molecular Technologies, Inc. BugBuster ${ }^{\circledR} 10 \mathrm{X}$ Protein Extraction Reagent was purchased from Sigma-Aldrich (cat. no. 70921). $\alpha$ fetoprotein (AFP) ELISA kit was purchased from Elabscience, Inc. (cat. no. E-EL-R0153c). Cytokeratin-19 (CK-19) antibody was obtained from Elabscience, Inc. (cat. no. E-AB-70083). Rabbit anti-rat primary antibodies targeted against Wnt-1 (cat. no. 27935-1-AP), $\beta$-catenin (cat. no. 66379-1-Ig), Cyclin D1 (cat. no. 60186-1-Ig), C-myc (cat. no. 67447-1-Ig), matrix metalloproteinase-7 (MMP-7; cat. no. 10374-2-AP), Axin2 (cat. no. 20540-1-AP), epithelial cell adhesion molecule (EpCAM; cat. no. 21050-1-AP) and GAPDH (cat. no. 10494-1-AP), as well as HRP-labeled goat anti-rabbit secondary antibodies (cat. no. PR30009) were purchased from Wuhan Sanying Biotechnology. FITC-labeled goat anti-mouse secondary antibodies (cat. no. BA1101) were purchased from Boster Biological Technology. RNAiso Plus, PrimeScript $^{\mathrm{TM}}$ reverse transcription (RT) reagent and SYBR Premix Ex Taq kits were purchased from Takara Biotechnology Co., Ltd. The Annexin V-FITC/PI cell apoptosis detection kit and cell cycle assay kits were bought from NanJing KeyGen Biotech Co., Ltd. (cat. no. KGA108). X-tremeGENE TM (cat. no. XTGHP-RO) was bought from Merck Sharp \& Dohme-Hoddesdon. The Wnt-1 plasmid was purchased from Guangzhou RiboBio Co., Ltd.

Preparation of KXRG-containing drug serum. A total of 20 male Sprague-Dawley rats weighing 200-220 g (7-8 weeks old) were obtained from the Hubei Provincial Center for Disease Control and Prevention. Rats were adapted to the new experimental environment for 3 days and received humanistic care based on the Guide for the Care and Use of Laboratory Animals of Institutional Animal Care and Use Committee of Hubei Provincial Hospital of Chinese Medicine. The housing conditions were as follows: Temperature, $20-25^{\circ} \mathrm{C}$; relative humidity, 40-70\%; 12-h light/dark cycle; fixed water supply system; and feed rate of three times per day. The present study was approved by the Hubei Provincial Hospital of Traditional Chinese Medicine Laboratory Animal Ethics Committee (Wuhan, China; approval no. 2019005).

KXRG was formulated into a $4.06 \mathrm{~g} / \mathrm{ml}$ stock solution with $0.9 \% \mathrm{NaCl}$. The rats were administered a dose that was $1 \mathrm{ml} / 100 \mathrm{~g}$ via gavage twice a day for 7 consecutive days. On the 7 th day, the rats were anesthetized by the intraperitoneal injection of $2 \%$ pentobarbital sodium $(40 \mathrm{mg} / \mathrm{kg})$. After successful anesthesia, 3-5 $\mathrm{ml}$ blood was drawn from the inferior vena cava of each rat. After 1-5 min, the rats were sacrificed by dislocation of the cervical vertebrae. The blood was then immediately poured into sterile EP tubes, and left to stand at room temperature for $0.5-1 \mathrm{~h}$ before centrifugation at $3,000 \mathrm{rpm}$ for $10 \mathrm{~min}$. Finally, the supernatant (serum) was removed and placed at $-80^{\circ} \mathrm{C}$.

Cell culture and KXRG administration. The rat HOC cell line WB-F344 was cultured in DMEM containing 10\% FBS at $37^{\circ} \mathrm{C}$ with $5 \% \mathrm{CO}_{2}$. The medium was replaced every 2-3 days. 
The cells were divided into the following groups: i) normal; ii) model; iii) high concentration of KXRG-containing serum (KXRG-H); iv) middle concentration of KXRG-containing serum (KXRG-M); and v) low concentration of KXRG-containing serum (KXRG-L) (16). With the exception of the normal group, cells were treated with $3 \mu \mathrm{g} / \mathrm{ml}$ MNNG prior to treatment with KXRG, which was used to induce the transformation of HOCs into hepatoma cells, for $24 \mathrm{~h}$ (17). and the cells in the normal group were treated with an equal amount of DMEM. Then, the original KXRG-containing drug serum was applied to the KXRG-H group, half of the concentration of the original KXRG-containing drug serum was applied to the KXRG-M group and a quarter of the concentration of the original KXRG-containing drug serum was applied to the KXRG-L group; FBS was used to prepare the half and one-quarter concentrations of the drug-containing serum. The cells in normal group and model group were treated with DMEM. The dosage of drug in each group was $20 \%$ of the culture medium. KXRG-treated cells were harvested after a 24-h incubation.

Flow cytometry. Apoptosis, the cell cycle and the expression of CK-19 protein were determined via flow cytometry. Cells were digested with $0.25 \%$ pancreatin (MedChemExpress; cat. no. HY-B2118) without EDTA. Rat HOC WB-F344 cells were collected and washed with PBS. Cell apoptosis was assessed using the AnnexinV-FITC/PI cell apoptosis detection kit according to the manufacturer's protocol. Briefly, cells were re-suspended in $500 \mu \mathrm{l}$ binding buffer mixed with $5 \mu \mathrm{l}$ AnnexinV-FITC, then mixed with $5 \mu \mathrm{l}$ PI and incubated at room temperature in the dark for $15 \mathrm{~min}$. The cell cycle was assessed using the cell cycle detection kit according to the manufacturer's protocol. Cells were washed with PBS, centrifuged with $350 \times \mathrm{g}$ for $5 \mathrm{~min}$ at $4^{\circ} \mathrm{C}$, fixed with pre-cooled $70 \%$ ethanol at $4^{\circ} \mathrm{C}$ for $1-2 \mathrm{~h}$, washed for a second time and the cell suspension was stained at $37^{\circ} \mathrm{C}$ for $15 \mathrm{~min}$ with $1 \mathrm{ml}$ PI/Triton X-100 (20 $\mu \mathrm{g}$ PI/0.1\% Triton X-100) containing $0.2 \mathrm{mg}$ RNase. In terms of CK-19 protein detection, the cells were washed with PBS, fixed with $4 \%$ paraformaldehyde at room temperature for $15 \mathrm{~min}$, washed for a second time with PBS, permeabilized with $0.5 \%$ Triton $\mathrm{X}-100$ for $10 \mathrm{~min}$ and added with CK-19 antibody at $4{ }^{\circ} \mathrm{C}$ for $24 \mathrm{~h}$. The apoptotic rate, cell cycle and expression of $\mathrm{CK}-19$ protein were detected by flow cytometry (BD Biosciences).

Cell transfection. When the cells grow to $70-80 \%$ confluence, 1:1/plasmid volume:DNA quality was selected to transfect cells. A serum-free medium of $8 \mathrm{ml}$ was added to a transfection tube. The DNA of Wnt-1 was shaken and added with $2 \mathrm{ml}$ X-tremeGENE TM (cat. no. XTGHP-RO) transfection reagent. The mixture was left at room temperature for 10-15 min. The medium was removed from the culture plate and wash it once with PBS. The mixture was added and the cells were returned to the incubator for $1 \mathrm{~h}$. The mixture was removed, then the complete medium was added and incubated at $37^{\circ} \mathrm{C}$ for $24 \mathrm{~h}$. The cells were subcultured again, and then were re-cultured in a $35-\mathrm{mm}$ Petri dish with a suitable density of $0.8 \times 10^{5}$ cells and underwent immunostaining. Cells were cultured under normal conditions for $48 \mathrm{~h}$ and then observed under a fluorescence microscope.
Immunofluorescence assays. To detect the expression of Wnt- 1 and $\beta$-catenin in cells, circular slides were placed in 24-well plates. Subsequently, WB-F344 cells were seeded $\left(1 \times 10^{4}\right)$ with $400 \mu 1$ DMEM per slide. After treatment with KXRG-containing serum, cells were fixed with $4 \%$ paraformaldehyde at $37^{\circ} \mathrm{C}$ for $30 \mathrm{~min}$. Cells were then permeabilized with $0.2 \%$ Triton $\mathrm{X}-100$ at $37^{\circ} \mathrm{C}$ for $20 \mathrm{~min}$, blocked with $5 \%$ BSA (Thermo Fisher Scientific, Inc.; cat. no. 37520 ) at $37^{\circ} \mathrm{C}$ for $30 \mathrm{~min}$, and then incubated with primary antibodies targeted against Wnt-1 (1:100) and $\beta$-catenin (1:100) at $4^{\circ} \mathrm{C}$ overnight. Slides were incubated with Cyanine 3- and FITC-labeled fluorescent secondary antibodies (both $1: 100$ ) at $37^{\circ} \mathrm{C}$ for $1 \mathrm{~h}$ in the dark, followed by staining with DAPI at $37^{\circ} \mathrm{C}$ for $5 \mathrm{~min}$ in the dark. Finally, slides were observed under a fluorescence microscope (magnification, $\mathrm{x} 400$ ).

ELISA. Cells were collected and centrifuged at $350 \mathrm{x} \mathrm{g}$ for $10 \mathrm{~min}$ at $4^{\circ} \mathrm{C}$, and the supernatant was suctioned. AFP levels in cell supernatants were determined by performing an ELISA using a rat AFP ELISA kit according to the manufacturer's protocol.

$R T$-quantitative PCR (RT-qPCR). Total RNA was extracted from WB-F344 cells using RNAiso Plus according to the manufacturer's protocol. To detect Wnt-1, $\beta$-catenin, Cyclin D1, C-myc, MMP-7, Axin2 and EpCAM expression levels, total RNA was reverse transcribed into cDNA using the PrimeScript RT Reagent Kit. The following temperature protocol was used for RT: $7^{\circ} \mathrm{C}$ for $15 \mathrm{~min}$ and $85^{\circ} \mathrm{C}$ for $5 \mathrm{sec}$. The StepOne Plus device (Applied Biosystems; Thermo Fisher Scientific, Inc.) was used to perform the qPCR reactions using the SYBR Premix Ex Taq kit according to the manufacturer's protocol. The following thermocycling conditions were used for qPCR: Initial denaturation at $95^{\circ} \mathrm{C}$ for $10 \mathrm{sec}$; and 40 cycles of $95^{\circ} \mathrm{C}$ for $5 \mathrm{sec}$ and $60^{\circ} \mathrm{C}$ for $20 \mathrm{sec}$. Relative mRNA expression levels were quantified using the $2^{-\Delta \Delta \mathrm{Cq}}$ method (18) and normalized to the internal reference gene GAPDH. All primers are listed in Table I and were synthesized by TsingKe Biological Technology.

Western blotting. The protein concentration was determined using the BCA method and the mass of protein loaded per lane was $1.0,0.8,0.6,0.4$ and $0.2 \mathrm{mg} / \mathrm{ml}$. After extracting proteins, the protein was loaded into SDS-PAGE gel (5\% concentrated, $12 \%$ separator) for separation. Separated proteins were transferred onto PVDF membranes, which were blocked at $4^{\circ} \mathrm{C}$ overnight with 5\% non-fat milk in PBS. The membranes were washed three times in Tris-buffered saline [Trise-Base (cat. no. 1115GR500), $\mathrm{HCl}$ (cat. no. GB622-89), DTT (cat. no. 1111GR005), SDS (cat. no. 30166428), bromophenol blue (cat. no. 71008060), glycerine (cat. no. 10010618)] with 5\% Tween-20 (TBST), and then incubated with primary antibodies at $4^{\circ} \mathrm{C}$ overnight. After being washed with TBST, the membranes were then incubated with HRP-labeled secondary antibodies at $3^{\circ} \mathrm{C}$ in a shaking table for $2 \mathrm{~h}$. Following a further wash with TBST, ECL (cat. no. P1050; Applygen Technologies, Inc.) was adopted to identify the immunoreactive bands. The densitometry analyses of the immunoreactive bands were performed using a Fuji ultrasonic-Doppler velocity profile (UVP) system and ImageJ software. GAPDH was used as the 
Table I. Gene primer sequences used for reverse transcriptionquantitative PCR.

\begin{tabular}{ll}
\hline Gene & \multicolumn{1}{c}{ Sequence $\left(5^{\prime} \rightarrow 3^{\prime}\right)$} \\
\hline GAPDH & F: ACAGCAACAGGGTGGTGGAC \\
& R: TTTGAGGGTGCAGCGAACTT \\
Wnt-1 & F: GAAACCGCCGCTGGAACT \\
& R: GAGGTGATTGCGAAGATAAACG \\
$\beta$-catenin & F: CTCTAGTGCAGCTTCTGGGTT \\
& R: AGATGGCAGGCTCGGTAATG \\
Cyclin D1 & F: CCCTGACACCAATCTCCTCAACGAC \\
& R: CTCCTCGCAGACCTCTAGCATCCAG \\
C-myc & F: CGAGCTGAAGCGTAGCTTTT \\
& R: CTCGCCGTTTCCTCAGTAAG \\
MMP-7 & F: GTGGACAAACTGAGGGAA \\
& R: CTAAGAACCGAGGCAAGT \\
Axin2 & F: CTATGCCTGTCTCCTCTAA \\
& R: GGTATCCACACATTTCTCC \\
EpCAM & F: ACGACGGTCTGTATGATCCC \\
& R: TAGGTCCTCACTCTCTCGGA
\end{tabular}

MMP, matrix metalloproteinase; EpCAM, epithelial cell adhesion molecule; F, forward; $R$, reverse.

loading control. The dilutions of the primary and secondary antibodies were as follows: Wnt-1, 1:1,000; $\beta$-catenin, 1:800; Cyclin D1, 1:1,000; C-myc, 1:1,000; MMP-7, 1:1,000; Axin2, 1:1,000; EpCAM, 1:1,000; and GAPDH, 1:2,000.

Statistical analysis. SPSS 13.0 (SPSS, Inc.) statistical software was used for data analysis. Data are presented as the mean $\pm \mathrm{SD}$, and the experiments were repeated three times. Comparisons among multiple groups were analyzed using one-way ANOVA followed by Tukey's post hoc test. $\mathrm{P}<0.05$ was considered to indicate a statistically significant difference.

\section{Results}

Effect of KXRG-containing serum on the apoptotic rate and cell cycle in MNNG-stimulated WB-F344 cells. As shown in Fig. 1A and B, compared with the normal group, the apoptotic rate and proportion of $\mathrm{S}$ phase cells were significantly increased in the model group $(\mathrm{P}<0.05)$. Following the addition of high and medium concentrations of KXRG-containing serum, the apoptotic rate and the proportion of $\mathrm{S}$ phase cells were significantly reduced compared with the model group $(\mathrm{P}<0.01)$. Furthermore, the apoptotic rate in the KXRG-L group was also significantly reduced compared with the model group $(\mathrm{P}<0.01)$.

Effect of KXRG-containing serum on CK-19 and AFP in $M N N G$-stimulated WB-F344 cells. As shown in Fig. 2A, compared with the normal group, the level of CK-19 protein in the model group was significantly higher $(\mathrm{P}<0.05)$. Following treatment with KXRG-containing serum, the level of CK-19 protein in cells decreased significantly $(\mathrm{P}<0.01)$. As shown in Fig. 2B, compared with the normal group, the concentration of AFP in the cell supernatant of the model group significantly increased $(\mathrm{P}<0.05)$. Following the addition of high and medium concentrations of KXRG-containing serum, the concentration of AFP decreased significantly compared with the model group $(\mathrm{P}<0.01)$.

Effect of KXRG-containing serum on the Wnt-1/ $\beta$-catenin signaling pathway in MNNG-stimulated WB-F344 cells. Subsequently, an immunofluorescence assay was performed to simultaneously detect the expression of Wnt- 1 and $\beta$-catenin in cells. As illustrated in Fig. 2C, compared with the normal group, the level of Wnt- 1 and $\beta$-catenin in the model group was increased. Following the addition of KXRG-containing serum, the level of Wnt-1 and $\beta$-catenin in cells decreased compared with the model group. As demonstrated in Fig. 3A and B, compared with the normal group, the mRNA expression levels of Wnt-1, $\beta$-catenin, Cyclin D1, C-myc, MMP-7, Axin2 and EpCAM in the model group were significantly increased $(\mathrm{P}<0.05)$. Addition of high and medium concentrations of KXRG-containing serum resulted in the mRNA expression levels of Wnt-1, $\beta$-catenin, Cyclin D1, C-myc, MMP-7, Axin2 and EpCAM reducing significantly compared with the model group $(\mathrm{P}<0.01)$. Moreover, the mRNA expression levels of Cyclin D1, C-myc and Axin2 in the KXRG-L group were also significantly decreased compared with the model group $(\mathrm{P}<0.01)$.

As displayed in Fig. 3C and D, compared with the normal group, the protein expression levels of Wnt-1, $\beta$-catenin, Cyclin D1, C-myc, MMP-7, Axin2 and EpCAM in the model group were significantly increased $(\mathrm{P}<0.05)$. Following the application of KXRG-containing serum, the protein expression levels of Wnt-1, $\beta$-catenin, Cyclin D1, C-myc, MMP-7, Axin 2 and EpCAM were significantly reduced $(\mathrm{P}<0.01)$, with the exception of MMP-7 in the KXRG-L group.

Effect of KXRG on the apoptotic rate, cell cycle and AFP in MNNG-stimulated WB-F344 cells following Wnt-1 overexpression. To determine the effects of Wnt-1 overexpression in WB-F344 cells, western blotting was performed to detect the Wnt-1 protein expression level in each group of cells. As exhibited in Fig. 4A, compared with the normal group, there was no significant change in Wnt-1 expression in the negative control group, whereas the Wnt-1 protein expression level in the Wnt1 overexpression group (Wnt-1-up) was significantly increased $(\mathrm{P}<0.05)$. As demonstrated in Fig. 4B and $\mathrm{C}$, compared with the normal group, the cell apoptotic rate and the proportion of $\mathrm{S}$ phase cells were significantly increased in the model group $(\mathrm{P}<0.05)$. Compared with the control group, the cell apoptotic rate and the proportion of $\mathrm{S}$ phase cells were further increased in the Wnt-1-up group $(\mathrm{P}<0.01)$. Following the addition of KXRG-containing serum, the cell apoptotic rate and the proportion of $\mathrm{S}$ phase cells were significantly reduced compared with the model group $(\mathrm{P}<0.01)$.

As displayed in Fig. 5, compared with the normal group, the level of intracellular CK-19 protein and the concentration of AFP in the cell supernatants were significantly increased in the model group $(\mathrm{P}<0.05)$. Compared with the model group, the level of intracellular CK-19 protein and the concentration 
A
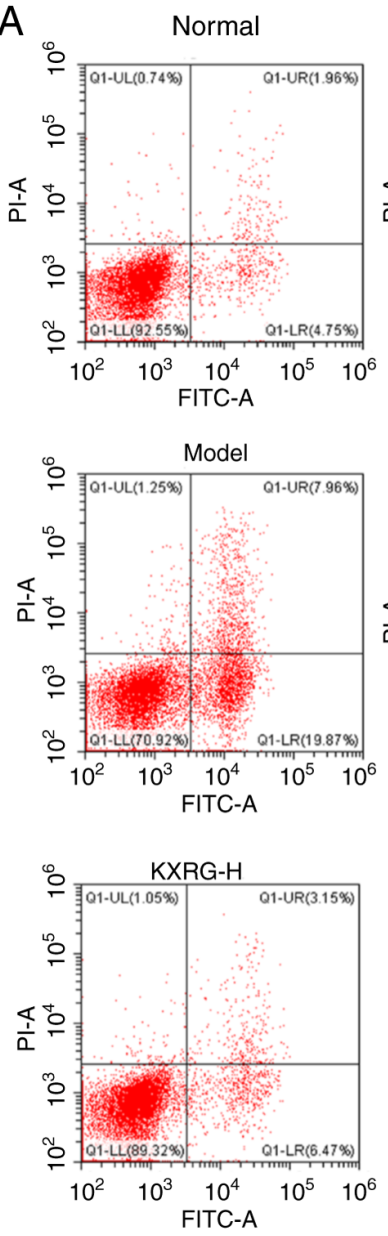

KXRG-M
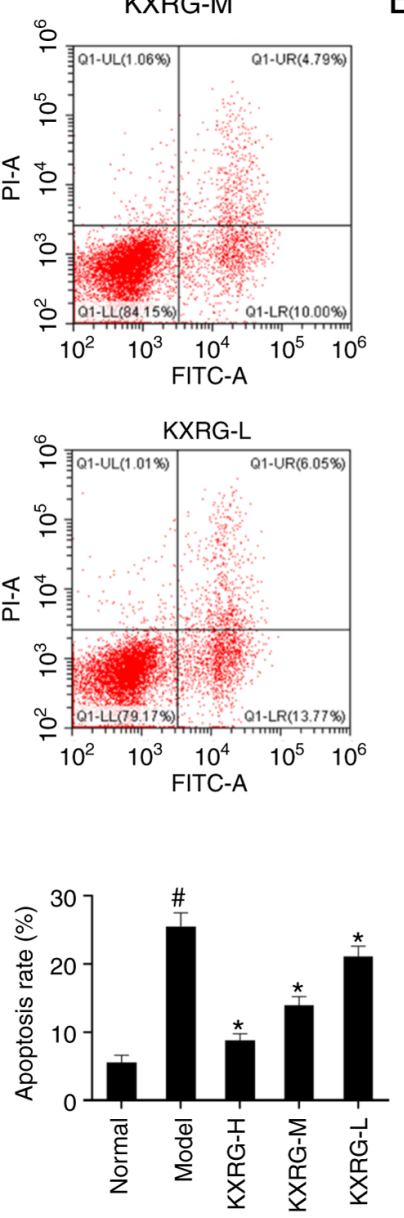

B
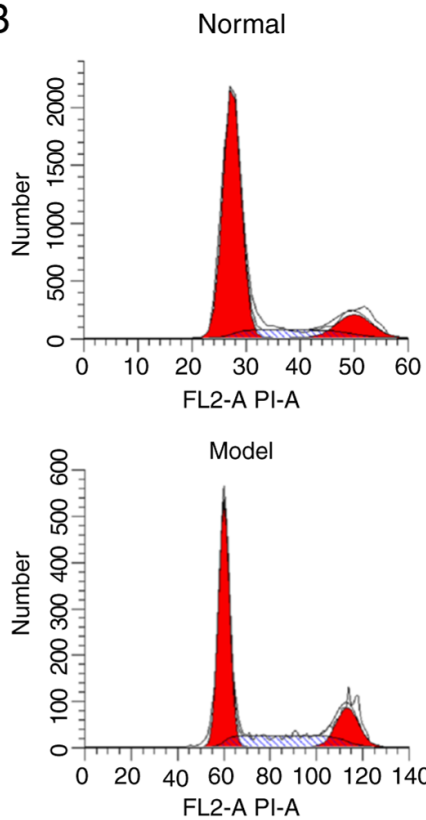

KXRG-H

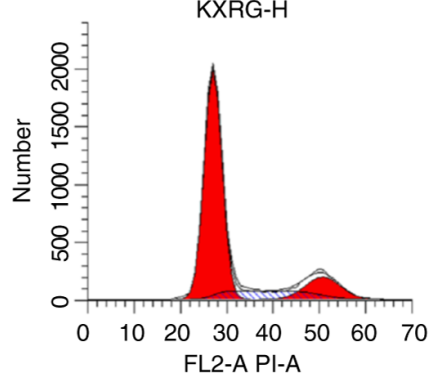

KXRG-M
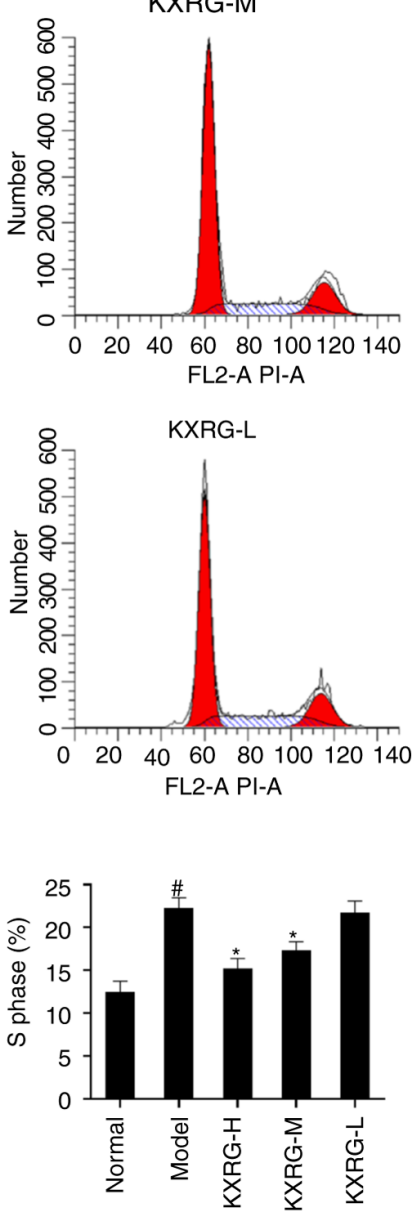

Figure 1. Effect of KXRG-containing serum on the apoptotic rate and cell cycle of MNNG-stimulated WB-F344 cells. (A) Flow cytometry was performed to detect the apoptotic rate of each treatment group. (B) Cell cycle phases of each treatment group were detected by flow cytometry. Data are presented as the mean \pm SD (n=3). ${ }^{\#} \mathrm{P}<0.05$ vs. normal; ${ }^{*} \mathrm{P}<0.01$ vs. model. KXRG, kangxianruangan granule; MNNG, N-methyl-N'-nitro-N-nitrosoguanidine; KXRG-H, high concentration of KXRG-containing serum; KXRG-M, middle concentration of KXRG-containing serum; KXRG-L, low concentration of KXRG-containing serum.

of AFP in the cell supernatant were further increased in the Wnt-1-up group $(\mathrm{P}<0.01)$. Compared with the model group, the level of CK-19 protein and the concentration of AFP were significantly decreased after adding KXRG-containing serum $(\mathrm{P}<0.01)$.

Effect of KXRG on the Wnt-1/ $\beta$-catenin signaling pathway in MNNG-stimulated WB-F334 cells following Wnt-I overexpression. As illustrated in Fig. 6, compared with the normal group, the levels of Wnt-1 and $\beta$-catenin in the model group were increased. Compared with the model group, the levels of Wnt-1 and $\beta$-catenin were further increased in the Wnt-1-up group. Following the addition of KXRG-containing serum, the levels of Wnt-1 and $\beta$-catenin in cells decreased compared with the model group.

As shown in Fig. 7A and B, compared with the normal group, the mRNA expression levels of Wnt-1, $\beta$-catenin, Cyclin D1, C-myc, MMP-7, Axin2 and EpCAM in the model group were all significantly increased $(\mathrm{P}<0.05)$. Compared with the model group, the mRNA expression levels of Wnt-1, $\beta$-catenin, Cyclin D1, C-myc, MMP-7, Axin2 and EpCAM were further increased in the Wnt-1-up group $(\mathrm{P}<0.01)$. Following treatment with KXRG-containing serum, the mRNA expression levels of Wnt-1, $\beta$-catenin, Cyclin D1, C-myc, MMP-7, Axin2 and
EpCAM were all significantly reduced compared with the model group $(\mathrm{P}<0.01)$.

As demonstrated in Fig. 7C and D, compared with the normal group, the protein expression levels of Wnt-1, $\beta$-catenin, Cyclin D1, C-myc, MMP-7, Axin2 and EpCAM in the model group were all significantly increased $(\mathrm{P}<0.05)$. Compared with the model group, the protein expression levels of Wnt-1, $\beta$-catenin, Cyclin D1, C-myc, MMP-7, Axin2 and EpCAM were further increased in the Wnt-1-up group $(\mathrm{P}<0.01)$. Following the addition of KXRG-containing serum, the protein expression levels of Wnt-1, $\beta$-catenin, Cyclin D1, C-myc, MMP-7, Axin2 and EpCAM were all significantly reduced compared with the Wnt-1-up group $(\mathrm{P}<0.01)$.

\section{Discussion}

The development of liver cancer is a multi-stage process that can be divided into three stages-initiation, promotion and progression (19). In the initial stages, irreversible gene mutations arise (20). In the promotion phase, clonal cell hyperplasia occurs but is generally considered to be reversible, which makes it an ideal period for the prevention of liver cancer (21). This phase also corresponds to the precancerous stage of liver cancer, with HOC proliferation being the primary pathological 
A
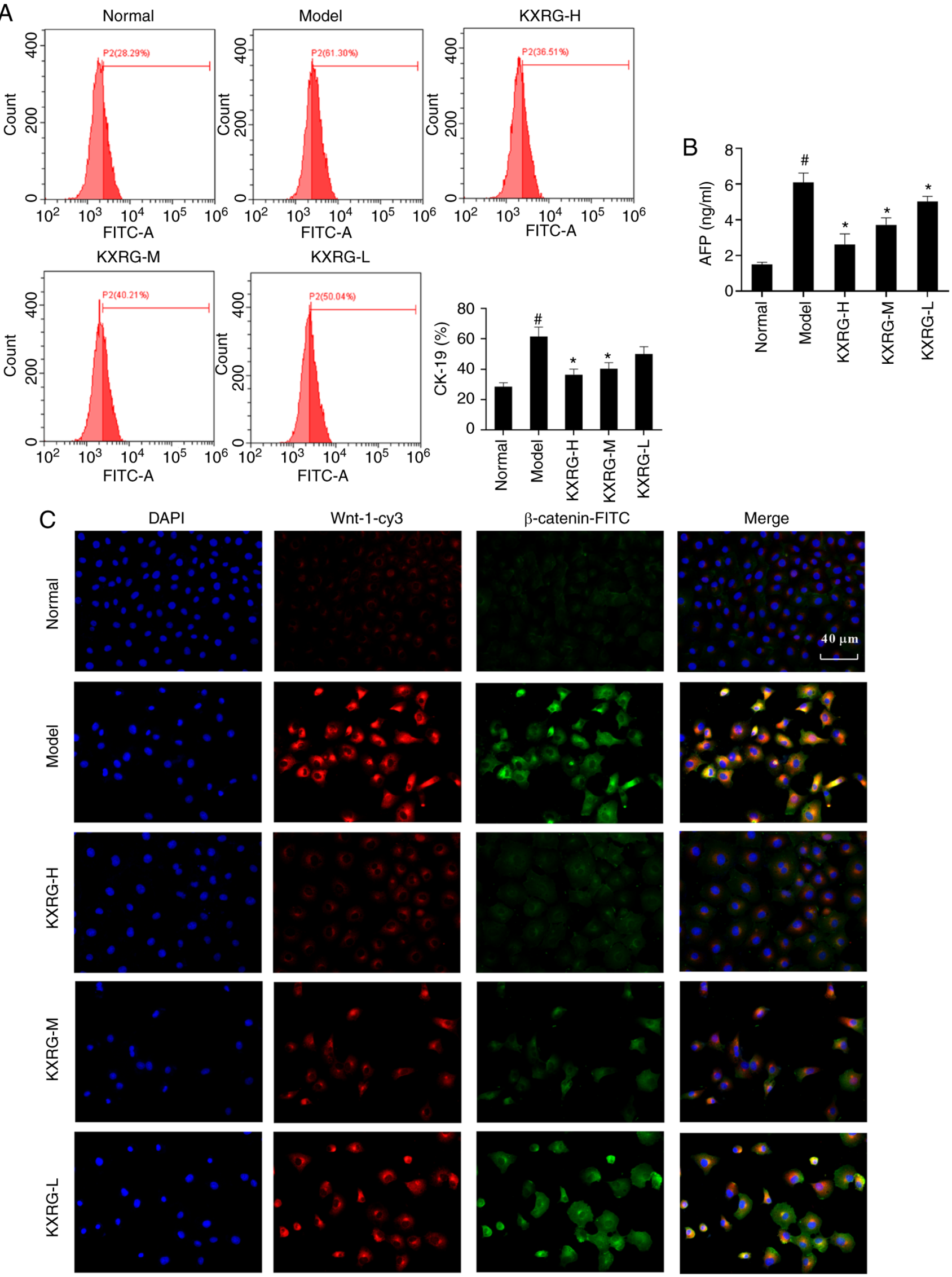

Figure 2. Effect of KXRG-containing serum on MNNG-stimulated tumor-related indexes in WB-F344 cells. (A) Expression of CK-19 protein in each treatment group was detected by flow cytometry. (B) Concentration of AFP protein in the supernatant of each treatment group was detected by performing ELISA. (C) Expression of Wnt-1 and $\beta$-catenin protein in each group was detected by performing an immunofluorescence assay (magnification, $\mathrm{x} 400$ ). Data are presented as the mean $\pm \mathrm{SD}(\mathrm{n}=3) .{ }^{*} \mathrm{P}<0.05$ vs. normal; ${ }^{*} \mathrm{P}<0.01$ vs. model. KXRG, kangxianruangan granule; MNNG, N-methyl-N'-nitro-N-nitrosoguanidine; KXRG-H, high concentration of KXRG-containing serum; KXRG-M, middle concentration of KXRG-containing serum; KXRG-L, low concentration of KXRG-containing serum; CK, cytokeratin; AFP, $\alpha$-fetoprotein; cy, cyanine. 

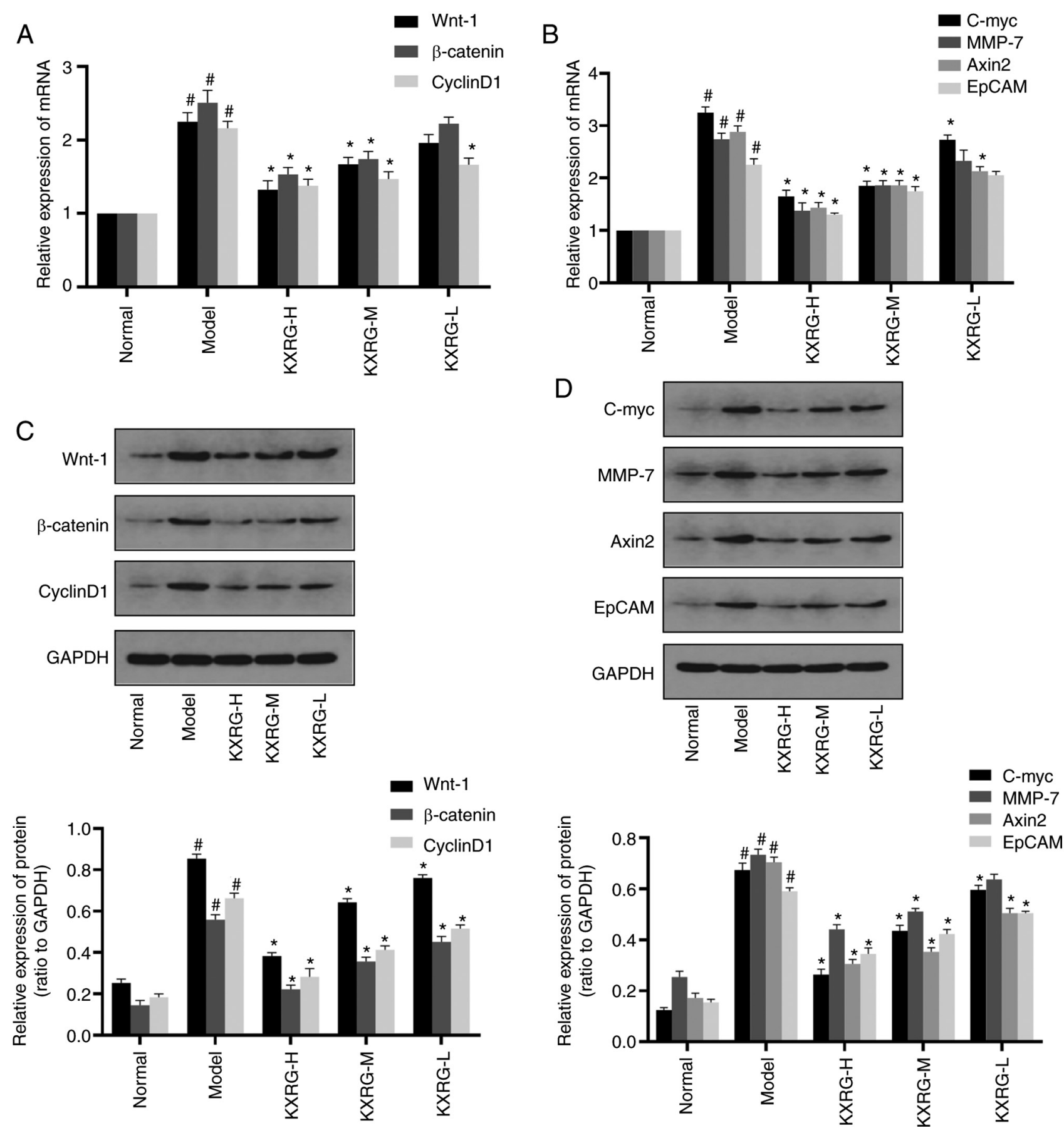

Figure 3. Effect of KXRG-containing serum on the Wnt-1/ $\beta$-catenin signaling pathway in MNNG-stimulated WB-F344 cells. mRNA expression levels of (A) Wnt-1, $\beta$-catenin, Cyclin D1, (B) C-myc, MMP-7, Axin2 and EpCAM were detected via reverse transcription-quantitative PCR. Protein expression levels of (C) Wnt-1, $\beta$-catenin, Cyclin D1, (D) C-myc, MMP-7, Axin2 and EpCAM were detected by performing western blotting. The data of the normal group are set to 1 and data are presented as the mean $\pm \mathrm{SD}(\mathrm{n}=3) .{ }^{\prime \prime} \mathrm{P}<0.05$ vs. normal; ${ }^{\prime} \mathrm{P}<0.01$ vs. model. KXRG, kangxianruangan granule; MNNG, $\mathrm{N}$-methyl-N'-nitroN-nitrosoguanidine; KXRG-H, high concentration of KXRG-containing serum; KXRG-M, middle concentration of KXRG-containing serum; KXRG-L, low concentration of KXRG-containing serum; MMP, matrix metalloproteinase; EpCAM, epithelial cell adhesion molecule.

feature (22). It should be noted that liver cirrhosis is considered a precancerous lesion (23). Previously, it has been demonstrated that HOCs can transform into HCC cells, resulting in liver cancer, a phenomenon that is referred to as the "cancer stem cell hypothesis' (24). As previously mentioned, when the liver is damaged, HOCs can either differentiate into liver cells for organ regeneration or transform into liver cancer cells $(11,24)$. Changes in the liver microenvironment may also lead to the malignant transformation of HOCs during the process of hyperplasia, which is involved in the initiation and promotion stages of hepatocarcinogenesis (25). The rat HOC line WB-F344 has previously been widely used in the modeling of precancerous lesions of liver. MNNG is an experimental carcinogen. Through its stimulation on WB-F344 cells, MNNG reproduces some of the conditions that appear during the transition from ad HOCs to HCC cells (17).

A recent study confirmed that abnormal activation of the Wnt- $1 / \beta$-catenin signaling pathway is a crucial factor in the 
A

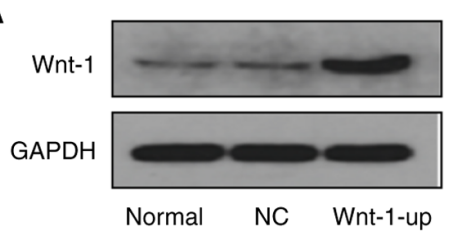

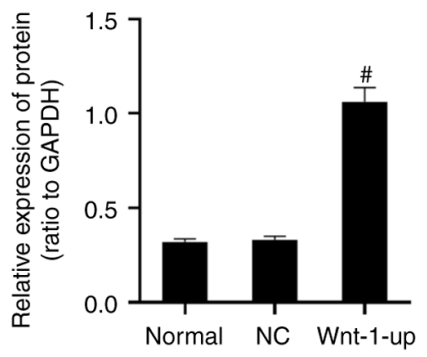

B
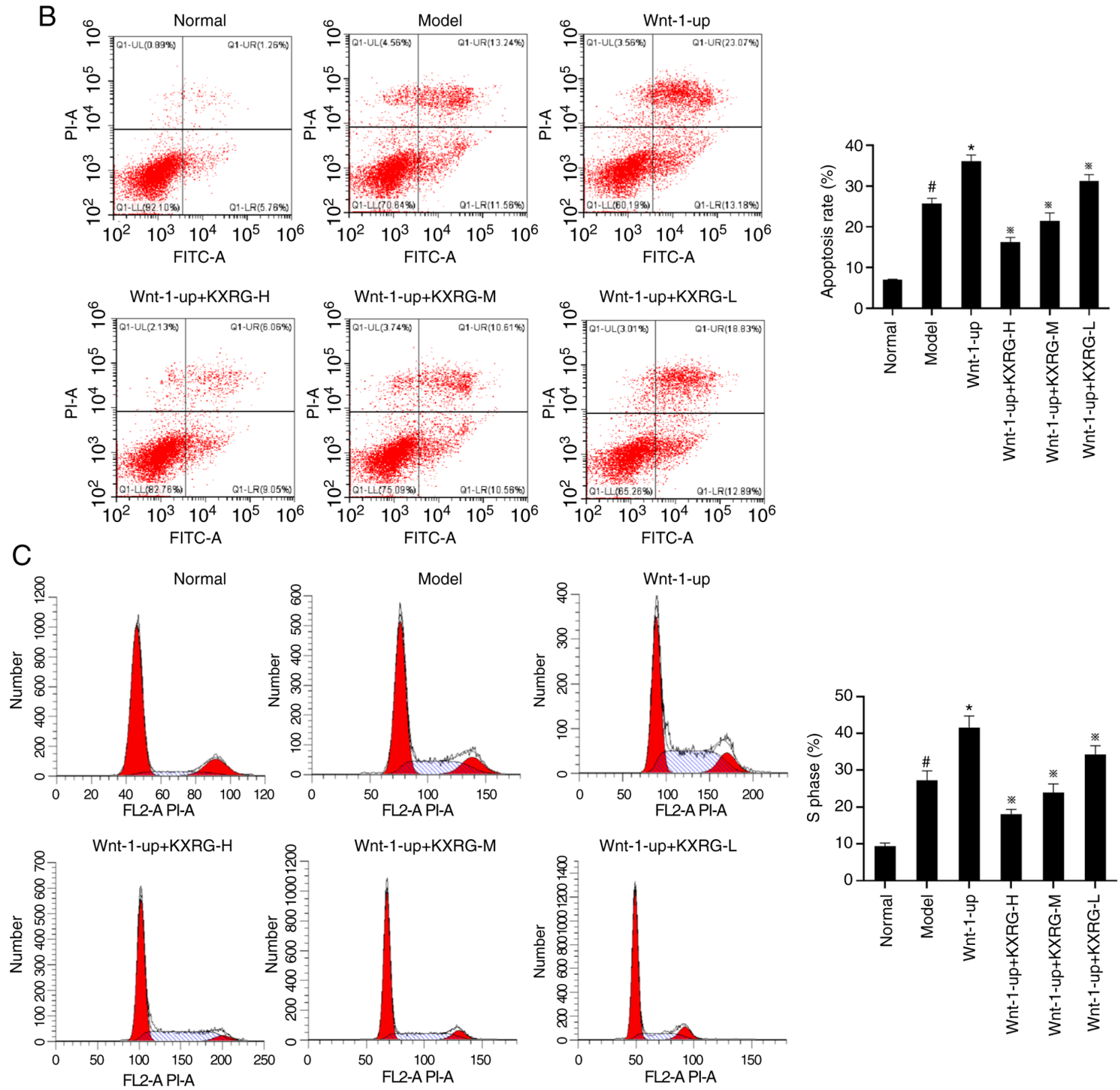

Figure 4. Effect of KXRG-containing serum on the apoptotic rate and cell cycle in MNNG-stimulated WB-F344 cells following Wnt-1 overexpression. (A) Protein expression level of Wnt-1 was detected by performing western blotting to confirm Wnt-1 overexpression in WB-F344 cells. (B) Flow cytometry was performed to detect the apoptotic rate of each group. (C) The cell cycle of each group was detected by flow cytometry. Data are presented as the mean \pm SD (n=3). " $\mathrm{P}<0.05$ vs. normal; ${ }^{*} \mathrm{P}<0.01$ vs. model; ${ }^{*} \mathrm{P}<0.01$ vs. Wnt-1-up. KXRG, kangxianruangan granule; MNNG, N-methyl-N'-nitro-N-nitrosoguanidine; KXRG-H, high concentration of KXRG-containing serum; KXRG-M, middle concentration of KXRG-containing serum; KXRG-L, low concentration of KXRG-containing serum; NC, negative control.

induction of hepatocarcinogenesis (26). It has been shown that the expression of Wnt proteins (Wnt-1 and Wnt-3) is increased in liver cancer tissues and cell lines (27). Therapeutic antibodies against Wnt proteins can reduce the proliferation and viability of liver cancer cells, inducing the apoptosis of tumor cells and inhibiting the activation of the Wnt- $1 / \beta$-catenin signaling pathway (28). The aberrant activation of the Wnt- $1 / \beta$-catenin signaling pathway is a signature in multiple 
A

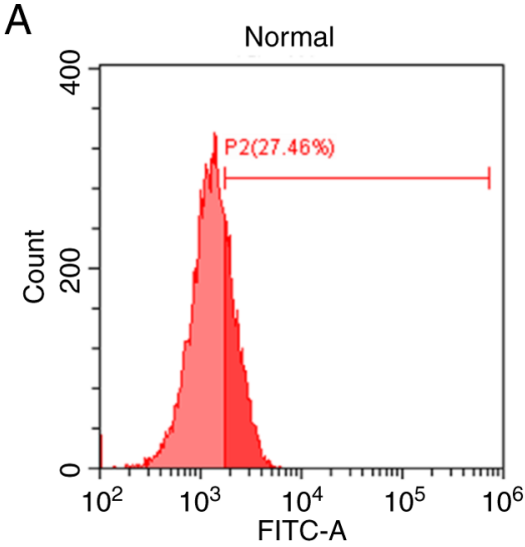

KXRG-H

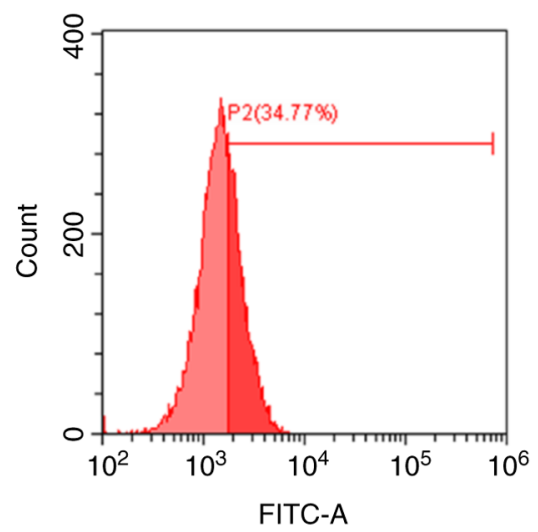

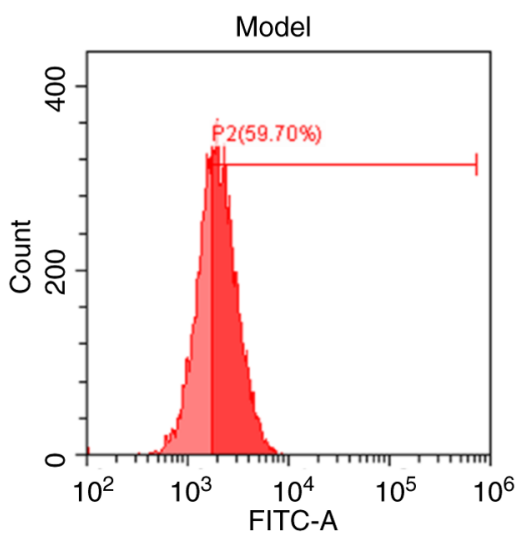

KXRG-M

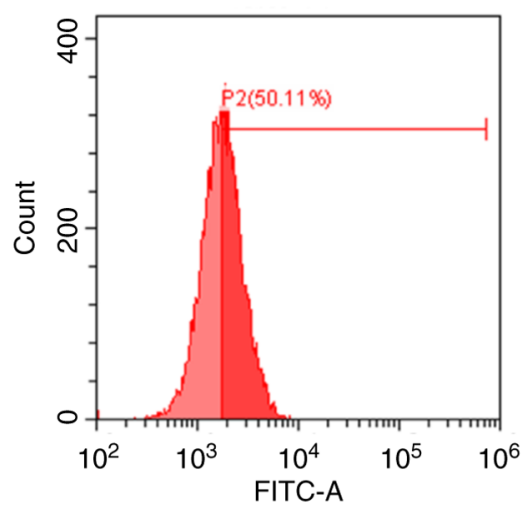

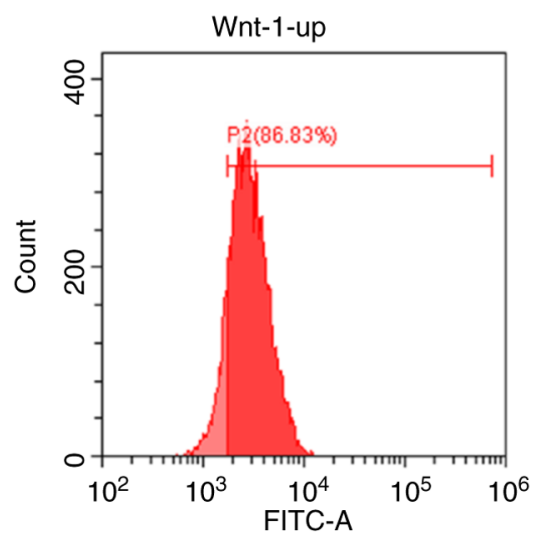

KXRG-L

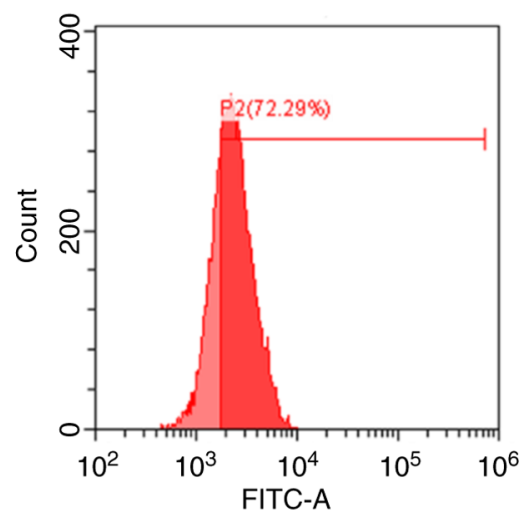

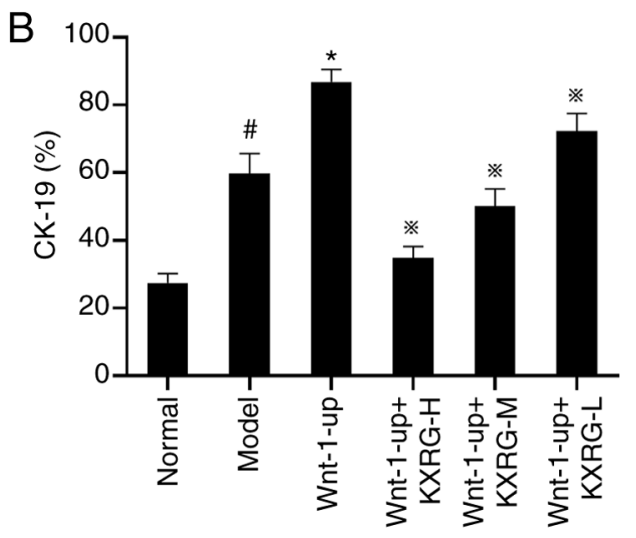

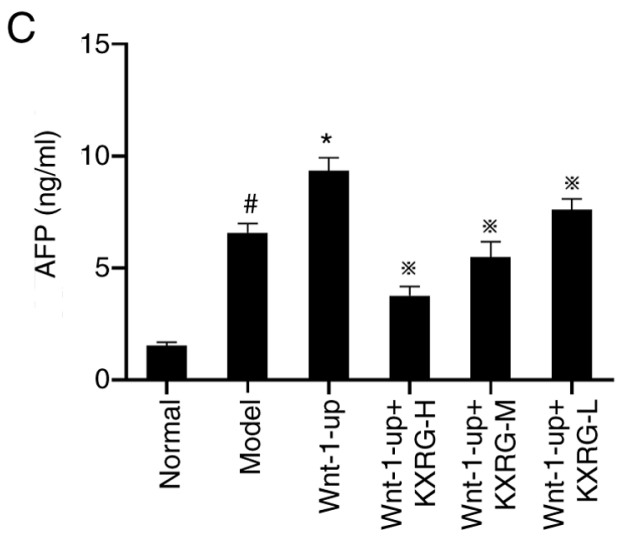

Figure 5. Effect of KXRG-containing serum on CK-19 and AFP in MNNG-stimulated, Wnt-1-overexpression WB-F344 cells. CK-19 protein expression was (A) detected by flow cytometry and (B) quantified. (C) Concentration of AFP protein in the supernatant of each group. Data are presented as the mean \pm SD (n=3). ${ }^{~} \mathrm{P}<0.05$ vs. normal. ${ }^{~} \mathrm{P}<0.01$ vs. model. ${ }^{*} \mathrm{P}<0.01$ vs. Wnt-1-up. KXRG, kangxianruangan granule; MNNG, N-methyl-N'-nitro-N-nitrosoguanidine; KXRG-H, high concentration of KXRG-containing serum; KXRG-M, middle concentration of KXRG-containing serum; KXRG-L, low concentration of KXRG-containing serum; CK, cytokeratin; AFP, $\alpha$-fetoprotein.

types of cancer, including HCC, making it a viable therapeutic target (29). $\beta$-catenin, a crucial component in this pathway (especially in the liver), displays a variety of functions, serving as a transcriptional co-activator and a cell-cell adhesion protein (26). Several proof-of-principle pre-clinical studies clearly demonstrated the potential of the therapeutic inhibition of $\beta$-catenin as a means of treatment for HCC (30). $\beta$-catenin serves a role in regulating cell proliferation, regeneration, differentiation and tumor migration, entering the cytoplasm from the cell membrane to the nucleus (31). In the nucleus, $\beta$-catenin interacts with the T-cell factor/lymphoid enhancer factor transcription factor family, stimulating the transcription of target genes, including Cyclin D1, C-myc, MMP-7, Axin2 and EpCAM, thus regulating cell proliferation and apoptosis $(32,33)$. The Wnt protein binds to the frizzled receptor, thereby affecting the Wnt- $1 / \beta$-catenin signaling pathway, and the activation and proliferation of HOCs (34).AFP and CK19 are markers of HOCs. When HOCs over-proliferate and transform into hepatoma cells, the expression levels of AFP and CK19 increase.

KXRG is a compound granule used in Chinese medicine, which contains seaweed, hawthorn, Salvia miltiorrhiza, Rhizoma Curcumae, Carapax Trionycis and oyster. These medicines together create a unique combination of Traditional Chinese 

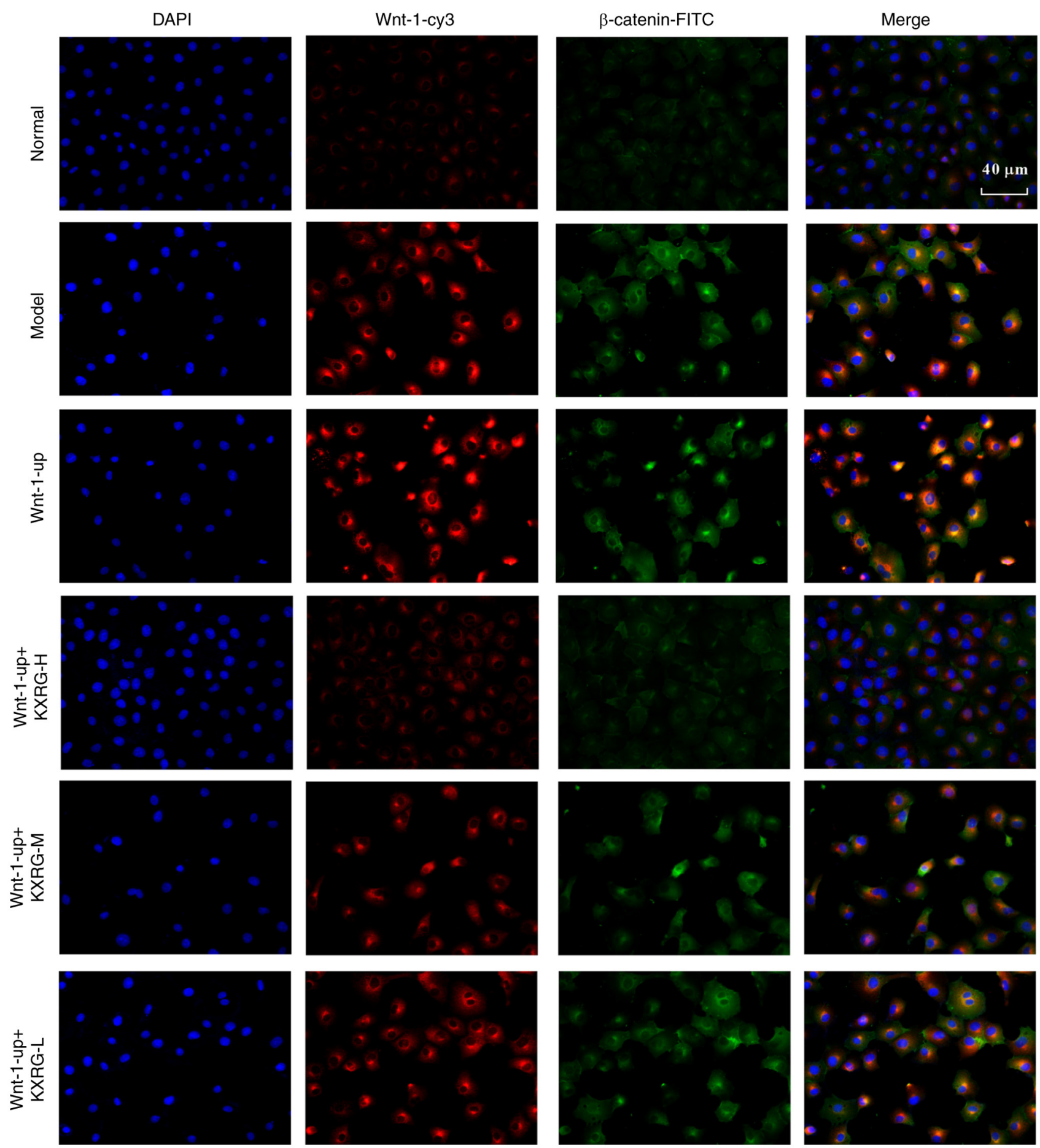

Figure 6. Effect of KXRG-containing serum on MNNG-stimulated WB-F344 cells following Wnt-1 overexpression. The expression of the Wnt- 1 and $\beta$-catenin proteins in each group was detected by performing an immunofluorescence assay (magnification, $\mathrm{x} 400$ ). KXRG, kangxianruangan granule; MNNG, N-methyl-N'nitro-N-nitrosoguanidine; KXRG-H, high concentration of KXRG-containing serum; KXRG-M, middle concentration of KXRG-containing serum; KXRG-L, low concentration of KXRG-containing serum; cy, cyanine.

Medicine, which has been used to treat liver fibrosis and cirrhosis in clinic and has a good curative effect $(35,36)$. The present study further explore its mechanism and potential effect.

In the present study, different concentrations of KXRG were applied to treat MNNG-induced WB-F344 cells. Compared with the normal group, the apoptotic rate, proportion of $\mathrm{S}$ phase cells, concentration of AFP in the cell supernatant, level of CK-19 protein, mRNA and protein expression levels of Wnt-1, $\beta$-catenin, Cyclin D1, C-myc, MMP-7, Axin2 and EpCAM in the model group were significantly increased. Following the application of KXRG, the aforementioned indicators were significantly reduced in MNNG-stimulated WB-F344 cells, suggesting that KXRG may inhibit the transformation of rat WB-F344 HOCs into liver cancer cells, potentially via inhibiting the expression of key genes and proteins in the Wnt- $1 / \beta$-catenin signaling pathway. Overexpression of Wnt-1 further increased the aforementioned indicators compared with the model group. The inhibitory effects of KXRG 


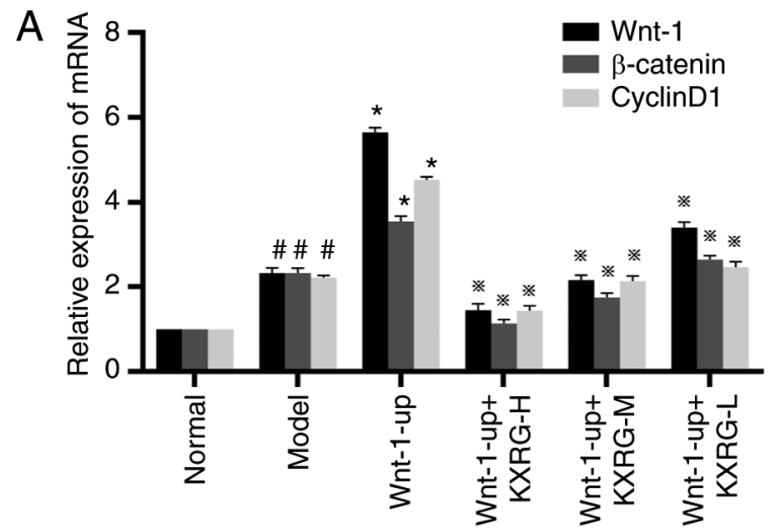

C
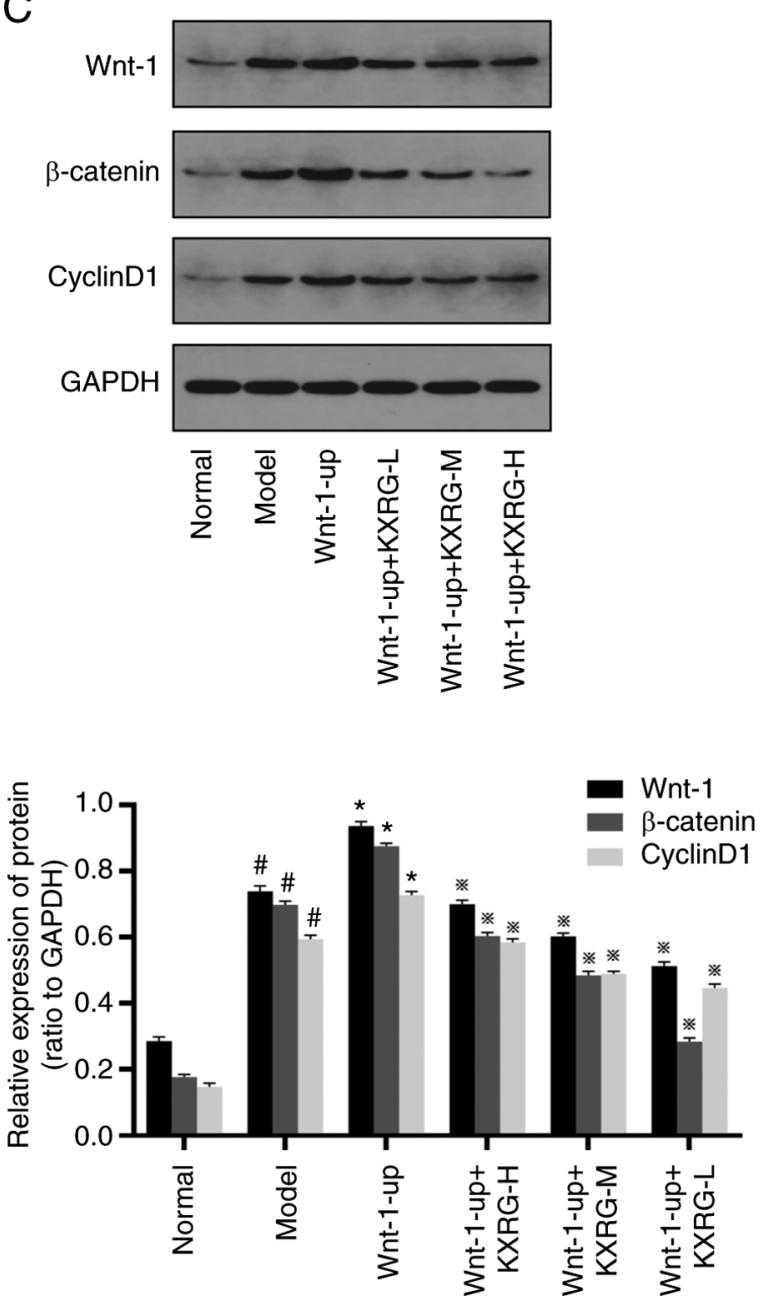

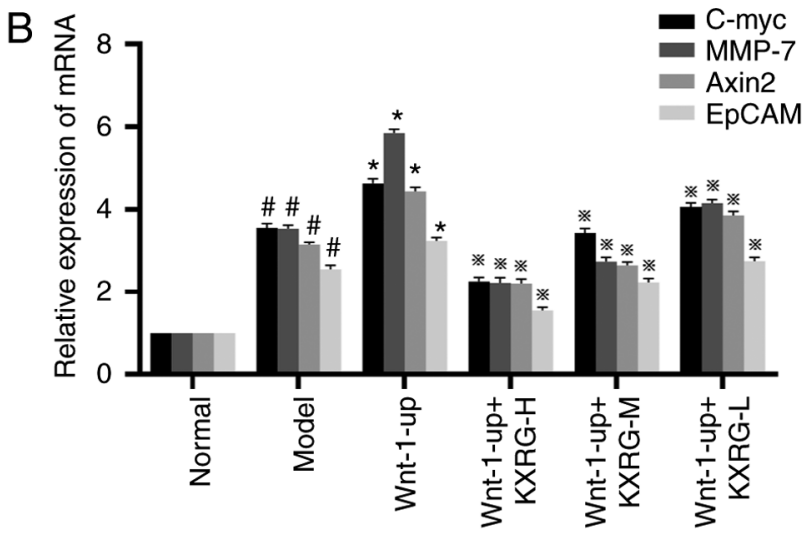

$\mathrm{D}$
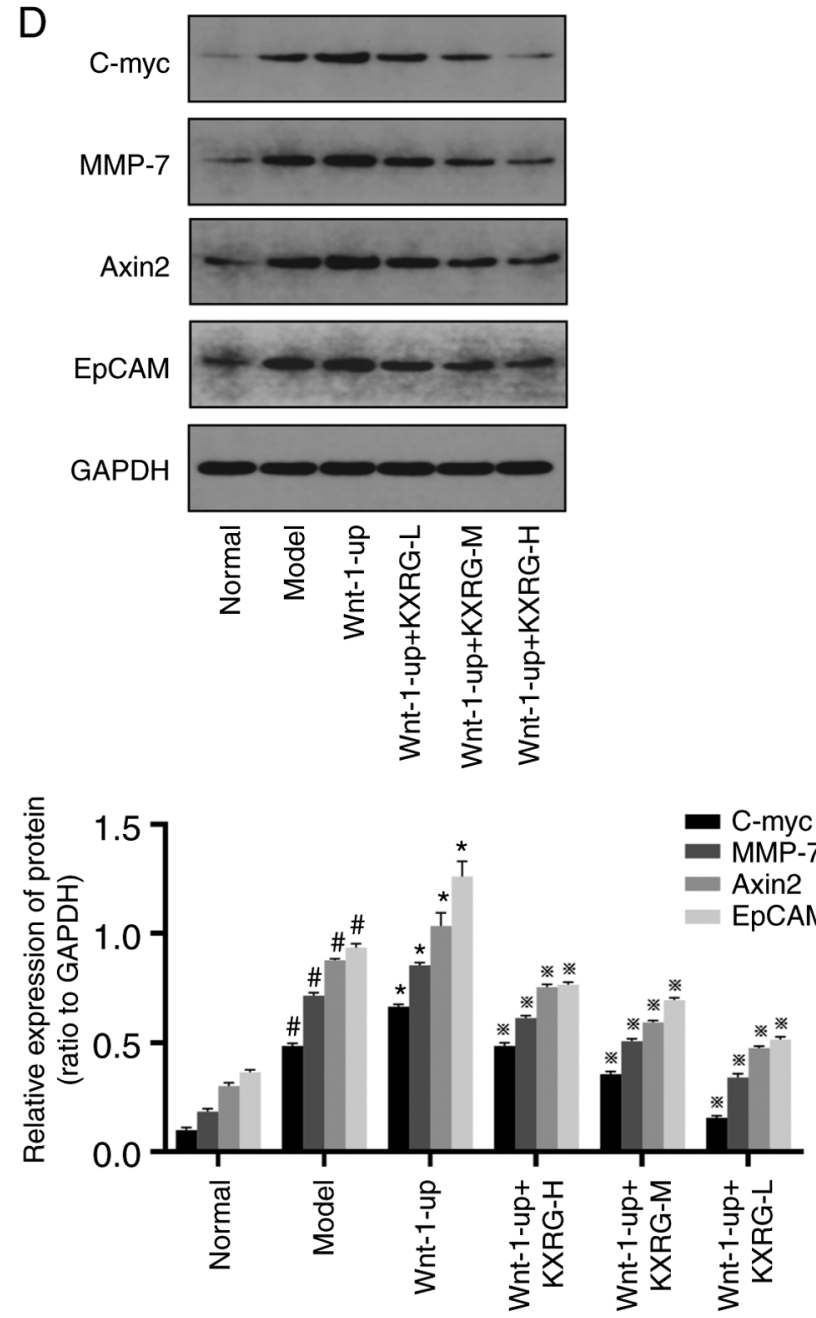

Figure 7. Effect of KXRG-containing serum on the Wnt-1/ $\beta$-catenin signaling pathway in MNNG-stimulated, Wnt-1-overexpression WB-F344 cells. mRNA expression levels of (A) Wnt-1, $\beta$-catenin, Cyclin D1, (B) C-myc, MMP-7, Axin2 and EpCAM were detected by reverse transcription-quantitative PCR. Protein expression levels of (C) Wnt-1, $\beta$-catenin, Cyclin D1,(D) C-myc,MMP-7, Axin2, and EpCAM detected by western blotting. The data of the normal group are set to 1 and data are presented as the mean $\pm \mathrm{SD}(\mathrm{n}=3) .{ }^{*} \mathrm{P}<0.05$ vs. normal; ${ }^{\mathrm{P}}<0.01$ vs. model; ${ }^{*} \mathrm{P}<0.01$ vs. Wnt-1-up. KXRG, kangxianruangan granule; MNNG, $\mathrm{N}$-methylN'-nitro-N-nitrosoguanidine; KXRG-H, high concentration of KXRG-containing serum; KXRG-M, middle concentration of KXRG-containing serum; KXRG-L, low concentration of KXRG-containing serum; MMP, matrix metalloproteinase; EpCAM, epithelial cell adhesion molecule.

continued to be present in cells overexpressing Wnt-1. These results suggested that the Wnt-1/ $\beta$-catenin signaling pathway may serve an important role in the development of HCC.

In conclusion, the present study indicated that KXRG activated the Wnt- $1 / \beta$-catenin signaling pathway, potentially inhibiting the transformation of rat WB-F344 HOCs to liver cancer cells. These findings lay a foundation for the study of the anti-fibrosis-hepatocarcinoma mechanism of drugs via the Wnt/ $\beta$-catenin pathway, and suggested a novel treatment option for patients with liver disease. However, due to the uncertainty of the composition of the serum containing the drug, it is not possible to determine the specific role of the monomer composition, which may be the focus of further research. 


\section{Acknowledgements}

The authors would like to thank Professor Lei Zhao of the Wuhan Union Hospital for guiding the construction of lentiviral vector and cell transfection.

\section{Funding}

The present study was supported by the Chinese Medicine Research Project grant from Health and Family Planning Commission of Hubei Province (grant no. ZY2019Z016).

\section{Availability of data and materials}

The datasets used and/or analyzed during the current study are available from the corresponding author on reasonable request.

\section{Authors' contributions}

As the leader of the whole project, FY designed the whole process of the experiment, participated in the data collection and analysis, and made a great contribution to the manuscript writing and revision. WT, JX and LL made important contributions to the design and operation of experiments, the processing of data, the production of images and the writing and revision of manuscripts. YW, XC and YL made important contributions to the experimental design, the optimization of the experimental procedure, the instruction of the experiment and data collection and analysis. DH, XW, TH and DL made important contributions to experimental design, data proofreading and manuscript writing and manuscript revision. FY and YW confirmed the authenticity of all the raw data. All authors read and approved the final manuscript.

\section{Ethics approval and consent to participate}

The present study was approved by the Hubei Provincial Hospital of Traditional Chinese Medicine Laboratory Animal Ethics Committee (Wuhan, China; approval no. 2019005).

\section{Patient consent for publication}

Not applicable.

\section{Competing interests}

The authors declare that they have no competing interests.

\section{References}

1. Yang JD, Hainaut P, Gores GJ, Amadou A, Plymoth A and Roberts LR: A global view of hepatocellular carcinoma: Trends, risk, prevention and management. Nat Rev Gastroenterol Hepato 116: 589-604, 2019.

2. Ferlay J, Colombet M, Soerjomataram I, Parkin DM, Piñeros M, Znaor A and Bray F: Cancer statistics for the year 2020: An overview. Int J Cancer: Apr 5, 2021 (Epub ahead of print). doi: 10.1002/ijc.33588.

3. Wang G, Wang Q, Liang N, Xue H, Yang T, Chen X, Qiu Z, Zeng C, Sun T, Yuan W, et al: Oncogenic driver genes and tumor microenvironment determine the type of liver cancer. Cell Death Dis 11: 313,2020
4. Lokau J, Schoeder V,Haybaeck J and Garbers C: Jak-stat signaling induced by interleukin- 6 family cytokines in hepatocellular carcinoma. Cancers (Basel) 11: 1704, 2019.

5. Chung MW, Ha SY, Choi JH, Park HJ, Myung DS, Cho SB Lee WS, Kim JW, Oh HH and Joo YE: Cardiac tamponade after radiofrequency ablation for hepatocellular carcinoma: Case report and literature review. Medicine (Baltimore) 97: e13532, 2018.

6. Yang YM, Kim SY and Seki E: Inflammation and liver cancer: Molecular mechanisms and therapeutic targets. Semin Liver Dis 39: 26-42, 2019.

7. Niu ZS, Niu XJ, Wang WH and Zhao J: Latest developments in precancerous lesions of hepatocellular carcinoma. World J Gastroenterol 22: 3305-3314, 2016.

8. Zheng T, Wang J, Jiang H and Liu LX: Hippo signaling in oval cells and hepatocarcinogenesis. Cancer Lett 302: 91-99, 2011

9. Shen Y and Cao DL: Hepatocellular carcinoma stem cells: Origins and roles in hepatocarcinogenesis and disease progression. Front Biosci (Elite Ed) 4: 1157-1169, 2012.

10. Chen JM, Chen L, Zern MA, Theise ND, Diehl AM, Liu P and Duan YY: The diversity and plasticity of adult hepatic progenitor cells and their niche. Liver Int 37: 1260-1271, 2017.

11. Xu RH, Zheng LY, He DL, Meng J, Xia LP, Hao XB and Zhang ZZ: Profiling of differentially expressed microRNAs (miRNAs) during differentiation of rat hepatic oval cells (HOCs) into hepatocellular carcinoma (HCC) cells. Clin Transl Oncol 17: 230-237, 2015.

12. Lecarpentier Y, Schussler O, Hebert JL and Vallee A: Multiple targets of the canonical WNT/ $\beta$-catenin signaling in cancers. Front Oncol 9: 1248, 2019.

13. Vilchez V, Turcios L, Marti F and Gedaly R: Targeting Wnt $/ \beta$-catenin pathway in hepatocellular carcinoma treatment. World J Gastroenterol 22: 823-832, 2016.

14. Gong S, Qu X, Yang S, Zhou S, Li P and Zhang Q: RFC3 induces epithelialmesenchymal transition in lung adenocarcinoma cells through the Wnt/ $\beta$-catenin pathway and possesses prognostic value in lung adenocarcinoma. Int J Mol Med 44: 2276-2288, 2019.

15. Cruz-Lozano M, Gonzalez-Gonzalez A, Marchal JA, Muñoz-MuelaE,Molina MP,CaraFE,Brown AM,García-Rivas G, Hernández-Brenes C, Lorente JA, et al: Hydroxytyrosol inhibits cancer stem cells and the metastatic capacity of triple-negative breast cancer cell lines by the simultaneous targeting of epithelial-to-mesenchymal transition, Wnt/ $\beta$-catenin and TGF $\beta$ signaling pathways. Eur J Nutr 58: 3207-3219, 2019.

16. Huang Y, Lin Y, Wu Y, Zeng J, Huang M, Guo S, Luo W, Lin $H$ and Lin Y: Molecular mechanisms of the inhibitory effects of jiangu granule-containing serum on RANKL-induced osteoclastogenesis. Mol Med Rep 16: 8420-8426, 2017.

17. Bi YH, Han WQ, Li RF, Wang YJ, Du ZS, Wang XJ and Jiang Y: Signal transducer and activator of transcription 3 promotes the Warburg effect possibly by inducing pyruvate kinase M2 phosphorylation in liver precancerous lesions. World J Gastroenterol 25: 1936-1949, 2019.

18. Livak KJ and Schmittgen TD: Analysis of relative gene expression data using real-time quantitative PCR and the 2-(Delta Delta C(T)) method. Methods 25: 402-408, 2001.

19. Shang W, Adzika G, Li Y, Huang Q, Ding N, Chinembiri B, Rashid MSI and Machuki JO: Molecular mechanisms of circular RNAs, transforming growth factor-beta, and long noncoding RNAs in hepatocellular carcinoma. Cancer Med 8: 6684-6699, 2019.

20. Hilmi M, Neuzillet C, Calderaro J, Lafdil F, Pawlotsky JM and Rousseau B: Angiogenesis and immune checkpoint inhibitors as therapies for hepatocellular carcinoma: Current knowledge and future research directions. J Immunother Cancer 7: 333, 2019.

21. Chao J, Zhao S and Sun H: Dedifferentiation of hepatocellular carcinoma: Molecular mechanisms and therapeutic implications. Am J Transl Res 12: 2099-2109, 2020.

22. Yu XT, Wang PY, Shi ZM, Dong K, Feng P, Wang HX and Wang XJ: Urotensin-II-mediated reactive oxygen species generation via NADPH oxidase pathway contributes to hepatic oval cell proliferation. PLoS One 10: e0144433, 2015.

23. Wu DB and Tang H: Advances in the study of cirrhosis and precancerous lesions of liver cancer. Zhonghua Gan Zang Bing Za Zhi 27: 483-486, 2019 (In Chinese).

24. Xu RH, Zheng LY, He DL, Meng J, Xia LP, Hao XB and Zhang ZZ: Retraction note to: Profiling of differentially expressed microRNAs (miRNAs) during differentiation of rat hepatic oval cells (HOCs) into hepatocellular carcinoma (HCC) cells. Clin Transl Oncol 17: 935, 2015. 
25. Liu J, Ruan B, You N, Huang Q, Liu W, Dang Z, Xu W, Zhou T, Ji R, Cao Y, et al: Downregulation of miR-200a induces EMT phenotypes and CSC-like signatures through targeting the betacatenin pathway in hepatic oval cells. PLoS One 8: e79409, 2013.

26. Perugorria MJ, Olaizola P, Labiano I, Esparza-Baquer A, Marzioni M, Marin JJG, Bujanda L and Banales JM: Wnt-beta-catenin signalling in liver development, health and disease. Nat Rev Gastroenterol Hepatol 16: 121-136, 2019.

27. Huang JL, Fu YP, Gan W, Liu G, Zhou PY, Zhou C, Sun BY, Guan RY, Zhou J, Fan J, et al: Hepatic stellate cells promote the progression of hepatocellular carcinoma through microRNA-1246ROR $\alpha$-wnt/ $\beta$-catenin axis. Cancer Lett 476: 140-151, 2020.

28. Li N, Wei L, Liu X, Bai HJ, Ye Y, Li D, Li N, Baxa U, Wang Q, Lv L, et al: A frizzled-like cysteine-rich domain in glypican-3 mediates wnt binding and regulates hepatocellular carcinoma tumor growth in mice. Hepatology 70: 1231-1245, 2019.

29. Wei W, Chua MS, Grepper S and So SK: Blockade of Wnt-1 signaling leads to anti-tumor effects in hepatocellular carcinoma cells. Mol Cancer 8: 76, 2009.

30. Fu X, Zhu X, Qin F, Zhang Y, Lin J, Ding Y, Yang Z, Shang Y, Wang L, Zhang QX and Gao Q: Linc00210 drives Wnt/ $\beta$-catenin signaling activation and liver tumor progression through CTNNBIP1-dependent manner. Mol Cancer 17: 73, 2018.

31. Monga SP: $\beta$-catenin signaling and roles in liver homeostasis, injury, and tumorigenesis. Gastroenterology 148: 1294-1310, 2015.
32. Doumpas N, Lampart F, Robinson MD, Lentini A, Nestor C, Cantù $\mathrm{C}$ and Basler $\mathrm{K}$ : TCF/LEF dependent and independent transcriptional regulation of $\mathrm{Wnt} / \mathrm{beta}$-catenin target genes. EMBO J 38: e98873, 2019.

33. Yang TW, Gao YH, Ma SY, Qiang W and Li ZF: Low-grade slightly elevated and polypoid colorectal adenomas display differential beta-catenin-TCF/LEF activity, c-Myc, and cyclin D1 expression. World J Gastroenterol 23: 3066-3076, 2017.

34. Rana MA, Ijaz B, Daud M, Tariq S, Nadeem T and Husnain T: Interplay of Wnt $\beta$-catenin pathway and miRNAs in HBV pathogenesis leading to HCC. Clin Res Hepatol Gastroenterol 43: 373-386, 2019.

35. Yan JS, Zhou JH and Cheng LB: Effect of Kangxian ruangan granule on hepatic fibrosis induced by tetrachloromethane and ethanol in rats. Chinese Journal of Integrated Traditional and Western Medicine on Liver Disease 27: 40-41, 2017.

36. Zhang CZ, Yan HM and Wang L: 31 cases of liver cirrhosis treated with Kangxian ruangan granule. Chinese Journal of Integrated Traditional and Western Medicine on Liver Disease 2: 19-20, 1999 (In Chinese)

(i) () () This work is licensed under a Creative Commons

EY No ND Attribution-NonCommercial-NoDerivatives 4.0 International (CC BY-NC-ND 4.0) License. 